\title{
Method Validation of Simvastatin Tablets for Estimating Acetone, Ethanol, Isopropyl Alcohol, and Dichloromethane by Gas Chromatograph with Head Space
}

\author{
K. Shivakanth Reddy*, Y. Keerthi Reddy, Sowmya Vennam \\ Scient Institute of pharmacy, Kanapuram, Ibrahimpatan, Telangana, India
}

*Corresponding author: Shivakanth, R.K., Scient Institute of pharmacy, Kanapuram, Ibrahimpatan, Telangana, India, E-mail: reddyshivakanth370@gmail.com

\begin{abstract}
A simple Gas Chromatography-Head Space(GC-HS) method for the determination of residual solvents in simvastatin tablets using Nitrogen as the carrier gas at $1.3 \mathrm{~mL} / \mathrm{min}$ with DB-624 (30 $\mathrm{m} \mathrm{X} 0.32 \mathrm{~mm}$ ID X $1.8 \mu \mathrm{m})$ as column using Flame Ionisation Detector(FID) as detector was developed. The developed method was validated and parameters were to be found within the limits of international conference on harmonization $(\mathrm{ICH})$ guidelines. The retention time for residual solvents individually and in spiked standard solution was determined. The \% RSD for six injections should be NMT15\%. The percentage recovery ranges from $80-120 \%$. The correlation coefficient $\mathrm{R}^{2} \geq 0.99$. The limit of detection and limit of quantification was found to be specific. Precision, method precision and intermediate precision was found to be within the acceptance limit. Finally the sample was tested for the presence of residual solvents mainly Isopropyl alcohol was found.
\end{abstract}

Received Date: March 09, 2017

Accepted Date: April 04, 2017

Published Date: April 10, 2017

Citation: Shivakanth, R.K., et al. Method Validation of Simvastatin Tablets for Estimating Acetone, Ethanol, Isopropyl Alcohol, and Dichloromethane by Gas Chromatograph with Head Space. (2017) J Anal Bioanal Sep Tech 2(1): 63-66.

DOI: $10.15436 / 2476-1869.17 .1414$

Keywords: Simvastatin, Gas chromatography, HMG Co-A, Residual solvents, DB- 624, ICH

\section{Introduction}

Statins, inhibitors of 3-hydroxy-3-methylglutaryl-coenzyme A (HMG-Co-A) reductase, have revolutionized the most efficient agents for reducing plasma cholesterol being also appreciated for their good tolerance. Angiographic studies have demonstrated that these compounds reduce the progression and may induce the regression of atherosclerosis. These effects were translated in significant cardiovascular morbidity and mortality reductions in many clinical trials (WOSCOPS, AFCAPS/ TeX CAPS, HS, CARE, LIPID, HPS). The beneficial effects of the HMG-Co-A reductase inhibitors are usually attributed to their capacity to reduce the endogenous cholesterol synthesis, by competently inhibiting the principal enzyme involved. Since mevalonate, the product of HMG Co A reductase reaction, is the precursor not only for cholesterol, but also for many other non-steroidal isoprenoid compounds, inhibition of this key enzyme may result in pleiotropic effects. They have been divided into two categories, involving: directly lipids, or intracellular signaling pathways. The first category includes: inhibition of cholesterol biosynthesis, increased uptake and degradation of low density lipoproteins (LDL), inhibition of the secretion of lipoproteins, inhibition of LDL oxidation, and inhibiton of the seavenger receptors expression. Statins modulate a series of processes leading to reduction of the accumulation of esterifies cholesterol into macrophages, increase of endothelial NO synthetase, reduction of the inflammatory process, increased stability of the inflammatory process, increased stability of the atherosclerotic plaques, restoration of platelets activity and of the coagulation process.

In addition, statins can inhibit tumor cells growth and enhance intracellular calcium mobilization. It was observed that inhibitors of $\mathrm{HMG}$ Co A reductase induce a reduction of the formation of osteoclast in rodents. Human subjects treated with stains have shown a reduction in the number of bone fractures.

The discovery of statins has led to an important progress in the primary and secondary prevention of coronary heart disease. Although angiographic modifications following statin therapy were modest. Clinical benefits that accompanied the therapy have been significant. Numerous clinical studies have correlated the reduction of blood cholesterol induced by these compounds with the reduction of the number of major coronary events, as well as general mortality in coronary patient. 


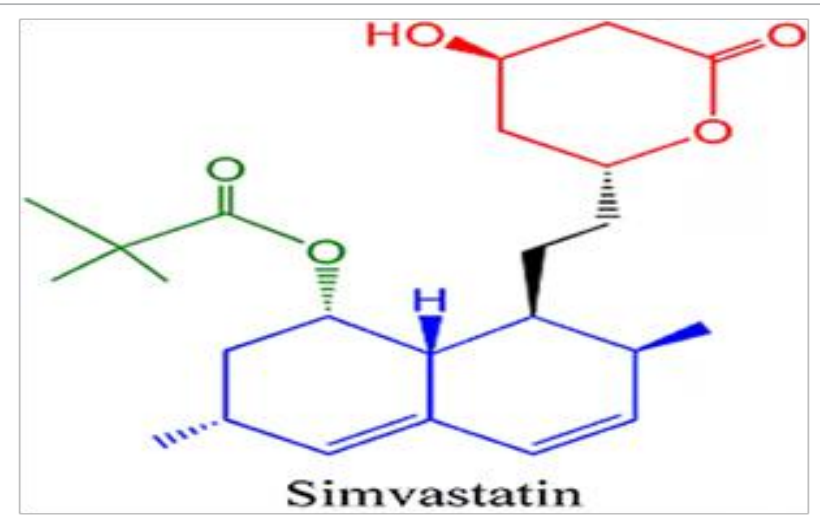

\section{Method Details}

Instrument Parameter

Instrument Name: GC, Make: SHIMADZU, Model: GC2010 Plus

\begin{tabular}{|l|c|}
\hline Column & $\begin{array}{l}\text { DB-624- 30m X 0.32 mm X 1.8 } \mu \mathrm{m} \text { or } \\
\text { equvqlent }\end{array}$ \\
\hline Flow rate & $1.3 \mathrm{ml} / \mathrm{min}$ \\
\hline Split Ratio & $1: 15$ \\
\hline Injection volume & $1.0 \mathrm{~mL}$ \\
\hline Carrier gas & Nitrogen \\
\hline Injection temp & $220^{\circ} \mathrm{c}$ \\
\hline Detector temp & $260^{\circ} \mathrm{c}$ \\
\hline Makeup flow & $30 \mathrm{~mL} / \mathrm{min}$ \\
\hline Hydrogen flow & $40 \mathrm{~mL} / \mathrm{min}$ \\
\hline Air flow & $400 \mathrm{ml} / \mathrm{min}$ \\
\hline Runtime & $17.33 \mathrm{~min}$ \\
\hline
\end{tabular}

Column Oven Temperature programme:

\begin{tabular}{|c|c|c|}
\hline Rate( $/ \mathbf{m i n})$ & Temp $^{\mathbf{c}}$ & Hold time(min) \\
\hline- & 40.0 & 03,00 \\
\hline 8.0 & 80.0 & 02,00 \\
\hline 30.0 & 240.0 & 02.00 \\
\hline
\end{tabular}

Head Space Parameters:

\begin{tabular}{|l|c|}
\hline GC Cycle Time & Off \\
\hline Needle temp & $100^{\circ} \mathrm{c}$ \\
\hline Transfer line temp & $110^{\circ} \mathrm{c}$ \\
\hline Sample platen temp & $90^{\circ} \mathrm{c}$ \\
\hline Sample equilibration time & $20 \mathrm{~min}$ \\
\hline Pressurize & $10 \mathrm{psi}$ \\
\hline Pressurization time & $1 \mathrm{~min}$ \\
\hline Pressurization equilibration time & $0.2 \mathrm{~min}$ \\
\hline Loop fill time & $1 \mathrm{~min}$ \\
\hline Loop fill pressure & $5 \mathrm{psi}$ \\
\hline Injection time & $1 \mathrm{~min}$ \\
\hline
\end{tabular}

Preparation of standards and sample

Diluent: Milli Q Water.
Preparation of Standard Solution: Taken $50 \mathrm{~mL}$ volumetric flask containing Diluents and add 15.9 $\mu \mathrm{L}$, of Acetone, $15.8 \mu \mathrm{L}$ of Ethanol, 16,0 $\mu \mathrm{L}$ of Isopropyl alcohol, $1.1 \mu \mathrm{L}$ of Dichloromethane and diluted up to the volume with Diluents, and mix well, transfer $2 \mathrm{~mL}$ of this solution into six Head Space vials and crimp tightly with septa.

Preparation of sample solution: Weigh accurately $100 \mathrm{mg}$ of sample into a $20 \mathrm{~mL}$ Head Space vial and add $2 \mathrm{~mL}$ of diluents and crimp the vial tightly with septa (prepared in duplicate).

\section{Method Validation}

The parameters like specificity, precision, linearity, accuracy, robustness, system suitability were performed that are mentioned in the international conference on harmonization (ICH) guidelines.

Specificity is performed to know the retention time for the residual solvents individually and in spiked sample solution.

Precision was validated to know the closeness of agreement between a series of measurements obtained from multiple sampling of the same homogenous sample. \% RSD for the precision was also found to be NMT15\%.

Linearity was done to know the test results which are directly proportional to the concentration of analyte in the sample. It was performed from LOQ to $100 \%$ and results were found to be within the limits.

Accuracy is the amount of the drug recovered from the spiked sample. It is assessed by 3 determinations over a minimum of 3 concentrations levels covering the specified range. Robustness is tested by introducing small variations in the method parameters. From the results it was observed that the method remain unaffected.

System suitability is performed to ensure that the complete testing system is suitable for intended application.

Finally the sample is checked for the presence of residual solvents especially Isopropyl alcohol.

\section{Results}

All the validated parameters were found to be within the limits. Linearity is performed from $20-100 \%$ and graph obtained was linear showing correlation coefficient $\mathrm{R}^{2} \geq 0.99 \%$. Drug recovery should be $80-120 \%$. System suitability for six injections \% RSD was found to be NMT 15\%. Insert (Table 1, table 2, Figure 1, Table 3, Figure 3, Table 4,Figure 2, Table 5, Figure 4, Table 6, Table 7)

Table 1: Specificity.

\begin{tabular}{|l|c|c|}
\hline \multirow{2}{*}{ Solvent Name } & \multicolumn{2}{|c|}{ Retention time } \\
\cline { 2 - 3 } & individual & spiked \\
\hline Ethanol & 3.673 & 3.679 \\
\hline Acetone & 4.145 & 4.147 \\
\hline Isopropyl alcohol & 4.375 & 4.376 \\
\hline Dichloromethane & 4.757 & 4.757 \\
\hline
\end{tabular}


Method Validation of Simvastatin Tablets for Estimating Acetone

\section{Linearity}

Table 2: Linearity table for Ethanol.

\begin{tabular}{|c|c|}
\hline Concentration(ppm) & Average area \\
\hline 1000 & 703336 \\
\hline 2000 & 1384218 \\
\hline 3000 & 2237968 \\
\hline 4000 & 2956703 \\
\hline 5000 & 3777422 \\
\hline correlation coefficient & 0.999 \\
\hline
\end{tabular}

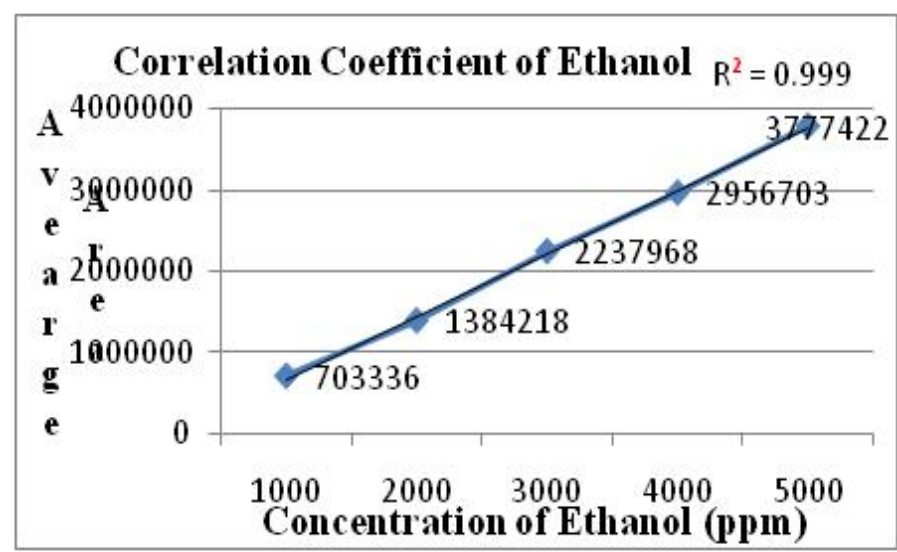

Figure 1: Linearity graph for Ethanol.

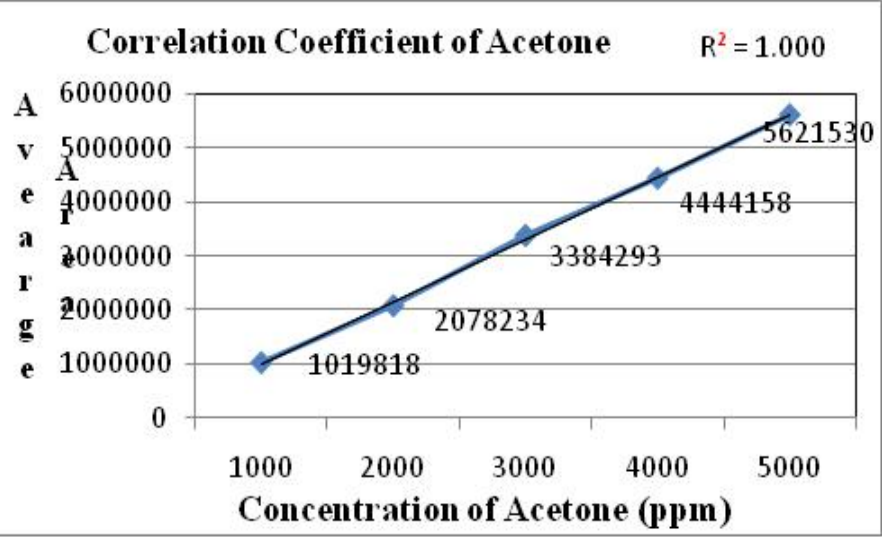

Figure 2: Linearity graph for Acetone.

Table 3: Linearity table for Acetone.

\begin{tabular}{|c|c|}
\hline Concentration(ppm) & Average area \\
\hline 1000 & 1019818 \\
\hline 2000 & 2078234 \\
\hline 3000 & 3384293 \\
\hline 4000 & 4444158 \\
\hline 5000 & 5621530 \\
\hline correlation coefficient & 1.000 \\
\hline
\end{tabular}

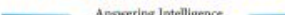

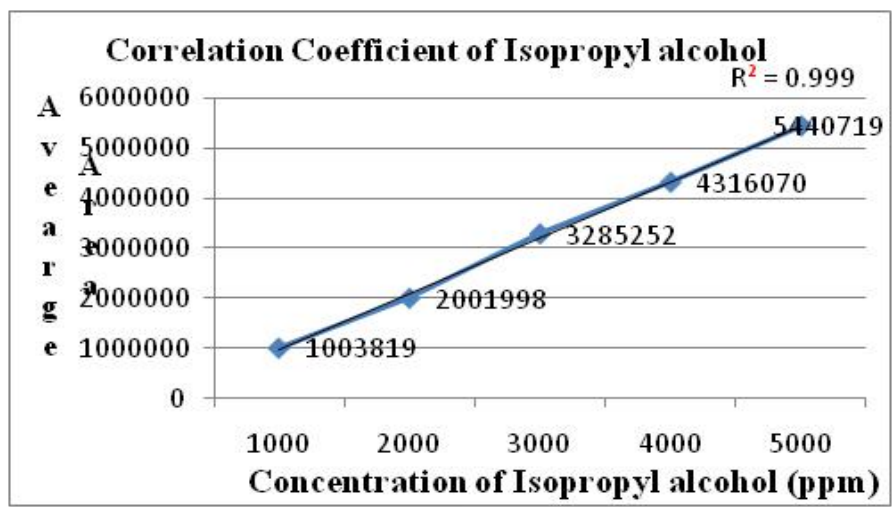

Figure 3: Linearity graph for Isopropyl alcohol.

Table 4: Linearity table for Isopropyl alcohol.

\begin{tabular}{|c|c|}
\hline Concentration(ppm) & Average area \\
\hline 1000 & 1003819 \\
\hline 2000 & 2001998 \\
\hline 3000 & 3285252 \\
\hline 4000 & 4316070 \\
\hline 5000 & 5440719 \\
\hline correlation coefficient & 0.999 \\
\hline
\end{tabular}

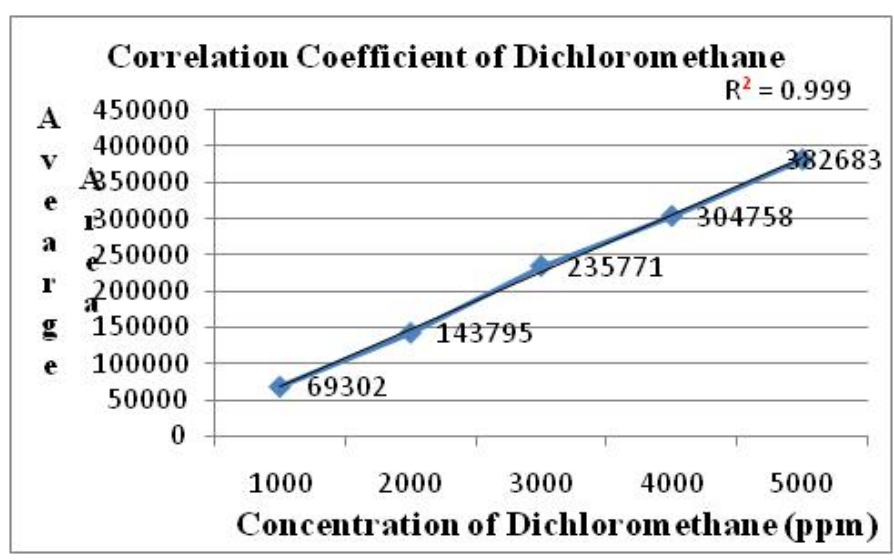

Figure 4: Linearity graph for Dichloromethane.

Table 5: Linearity table for Dichloromethane.

\begin{tabular}{|c|c|}
\hline Concentration(ppm) & Average area \\
\hline 1000 & 69302 \\
\hline 2000 & 143795 \\
\hline 3000 & 235771 \\
\hline 4000 & 304758 \\
\hline 5000 & 382683 \\
\hline correlation coefficient & 0.999 \\
\hline
\end{tabular}


Method Validation of Simvastatin Tablets for Estimating Acetone

\begin{tabular}{|c|c|c|c|c|}
\hline \multirow{2}{*}{$\begin{array}{c}\text { concentration } \\
\text { in } \%\end{array}$} & \multicolumn{4}{|c|}{ Average \% Recovery } \\
\hline & Ethanol & Acetone & IPA & MDC \\
\hline LOQ & 81.20 & 87.63 & 81.40 & 94.85 \\
\hline $50 \%$ & 82.29 & 89.18 & 82.98 & 93.59 \\
\hline $100 \%$ & 94.60 & 95.38 & 92.73 & 97.84 \\
\hline $150 \%$ & 86.66 & 87.65 & 84.93 & 97.27 \\
\hline
\end{tabular}

Table 7: LOD and LOQ.

\begin{tabular}{|c|c|c|c|c|}
\hline Solvent & Ethanol & Acetone & IPA & MDC \\
\hline LOD & 195 & 182 & 207 & 29 \\
\hline LOQ & 591 & 551 & 628 & 88 \\
\hline
\end{tabular}

\section{Robustness}

The flow rate was changed $\pm 0.2 \mathrm{~mL} / \mathrm{min}$ from that of the original one i.e. $1.3 \mathrm{~mL} / \mathrm{min}$, The Column oven temperature was changed $\pm 4^{\circ} \mathrm{c}$ from the original value i.e. $40^{\circ} \mathrm{c}$, and The Temperature of detector was changed $\pm 5^{\circ} \mathrm{c}$ from the original value i.e. $260^{\circ} \mathrm{c}$. The obtained results show that it has not affected by change in Flow rate, Column oven Temperature, and Detector Temperature.

\section{Batch Analysis}

Finally the prepared simvastatin tablets were tested for the presence of residual solvents. Prepare the test solution in duplicate consecutively for the single batch injects the prepared two tests solutions into the gas chromatography and record the peak responses. Subtract the area counts at solvent retention time in blank injection from the area counts obtained due to test preparation. Calculate the content in ppm of residual solvents by using average area from test solution against to the solvent peak areas obtained from six standard injections

\section{Following Formulae}

\section{Calculation}

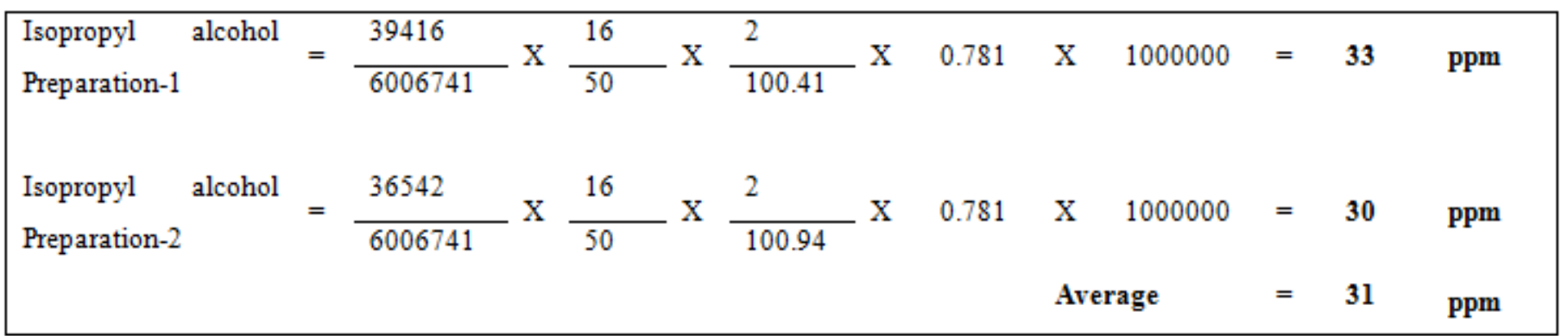

Results of Sample Preparations

\begin{tabular}{|l|c|c|c|c|}
\hline & $\begin{array}{c}\text { Ethanol } \\
\text { (Result in ppm) }\end{array}$ & $\begin{array}{c}\text { Acetone } \\
\text { (Result in ppm) }\end{array}$ & $\begin{array}{c}\text { Isopropyl alcohol } \\
\text { (Result in ppm) }\end{array}$ & $\begin{array}{c}\text { Dichloromethane } \\
\text { (Result in ppm) }\end{array}$ \\
\hline Preparation-1 & BDL & BDL & 33 & BDL \\
\hline Preparation-2 & BDL & BDL & 30 & BDL \\
\hline Average & BDL & BDL & 32 & BDL \\
\hline
\end{tabular}

\section{Conclusion}

From the results obtained we can conclude that all the acceptance criteria i.e. \%RSD for at least of six injections is NMT $15 \%$ as per USP. From the batch analysis Isopropyl alcohol was found about $32 \mathrm{ppm}$ in the sample.

Acknowledgement: The author thanks to the Star tech labs Pvt. Ltd. for providing all the facilities to our work.

\section{References}

1. European medicines agency 2009. ICH topic Q3C (R4) impurities, Guidelines for residual solvents.

Others

2. Camarasu, C.C, Szuts, M.M., Varga, G.B. Residual solvents in pharmaceutical products by GC-HS and GC-MS-SPME. (1998) J pharma Biomed Anal 18(4-5): 623-638.

Crossref $\mid$ Others

3. ICH guide lines
Ommega Online Publisher

Journal of Analytical, Bioanalytical and Separation Techniques

Short Title : J Anal Bioanal Sep Tech
E-mail: analyticaltech@ommegaonline.com website: www.ommegaonline.org 